\title{
ANTEROPOSTERIOR RADIOGRAPHS OF THE OSTEOARTHRITIC KNEE
}

\author{
SAM S. MESSIEH, PETER J. FOWLER, TOM MUNRO
}

From the University Hospital, Ontario

\begin{abstract}
Destruction of the articular cartilage is the first change seen on gross examination of the knee in osteoarthritis. Weight-bearing radiographs are conventionally taken with the knee in full extension. Biomechanical studies have shown, however, that the major contact stresses in the femorotibial articulation occur when the knee is flexed about $28^{\circ}$. Arthroscopy has confirmed that cartilage loss occurs in a more posterior portion of the femoral condyles than is revealed by radiographs taken in full extension. The 'standing tunnel view' is a weight-bearing postero-anterior radiograph taken with the knee in $30^{\circ}$ of flexion. The radiographs of 64 patients have been used to compare the conventional with the standing tunnel view. In 10 knees in which the conventional view suggested normal cartilage the standing tunnel view revealed severe degeneration.
\end{abstract}

Destruction of the articular cartilage is the first change seen on gross examination of the knee in osteoarthritis. Non-weight-bearing radiographs have limited value in assessing the degree of cartilage loss: weight-bearing views have been advocated but are conventionally done with the patient's knees in full extension (Leach, Gregg and Siber 1970). Although weight-bearing views record the width of the cartilage space more accurately, the joint space often appears to be normal in patients who, in fact, have severe cartilage loss.

Why is there this discrepancy, and what can we do to obtain a more reliable estimate of cartilage thickness? We have observed, at arthroscopy, that destruction of the cartilage occurs in a more posterior site on the femoral condyles than is shown by the conventional standing view. Biomechanical studies have shown that the major contact stresses in the tibiofemoral articulation occur with the knee in about $28^{\circ}$ flexion (Maquet 1976). This suggested that standing anteroposterior radiographs with the knee slightly flexed would be of more value than conventional views taken in extension.

\section{METHOD}

Over a three-month period, patients undergoing evaluation for osteoarthritis of the knee had a conventional standing radiograph in extension (Fig. 1) and a 'standing

S. S. Messieh, MD, FRCS C

P. J. Fowler, MD, FRCS C, Associate Professor, Orthopaedic Surgery T. Munro, MD, FRCP C, Associate Professor, Radiology

University of Western Ontario, London, Ontario, Canada N6A 5A5.

Correspondence should be sent to Dr S. S. Messieh at 2559 Caroline Avenue, Columbus, Ohio, USA 43209.

(C) 1990 British Editorial Society of Bone and Joint Surgery 0301-620X/90/4119\$2.00

J Bone Joint Surg [Br] 1990; 72-B:639-40.

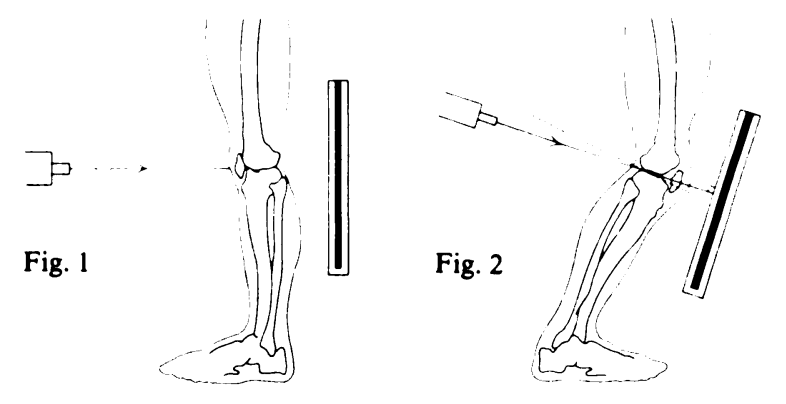

Anteroposterior weight-bearing radiographs. Figure 1 - In full extension. Figure 2 - In $30^{\circ}$ flexion the 'standing tunnel view'.

tunnel view', a postero-anterior radiograph taken with the knee in $30^{\circ}$ of flexion and the X-ray tube angled $22^{\circ}$ caudally (Fig. 2). We examined 64 patients; the radiographs were subsequently reviewed and the joint spaces measured at the mid-point of the affected tibiofemoral compartment.

\section{RESULTS}

We measured 198 tibiofemoral compartments. In 10 knees there was a normal joint space on the conventional views but marked narrowing on the standing tunnel views (average difference, $3.2 \mathrm{~mm}$ ). This was seen in both medial (Fig. 3) and lateral compartments (Fig. 4). In 32 compartments there was over $2 \mathrm{~mm}$ difference in joint space between the two views. In only four cases was the space wider on the tunnel view.

\section{DISCUSSION}

Marklund and Myrnets (1974) and Railhac et al (1981) have already reported that weight-bearing radiographs taken in slight flexion reflect the width of the cartilage space most accurately. The biomechanical studies of 


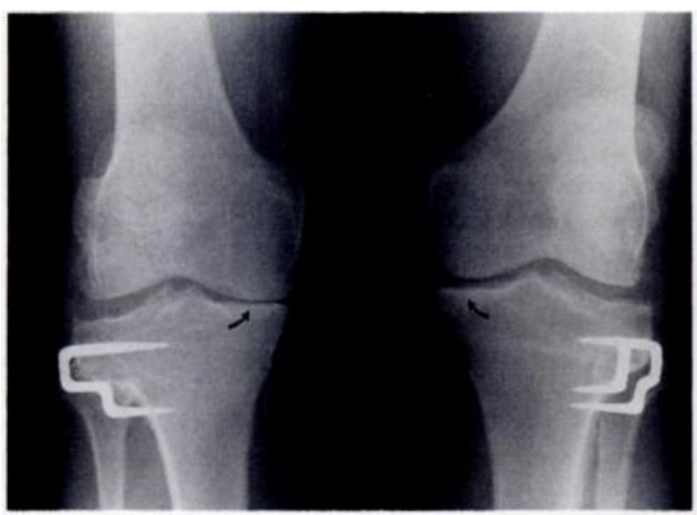

Fig. 3a

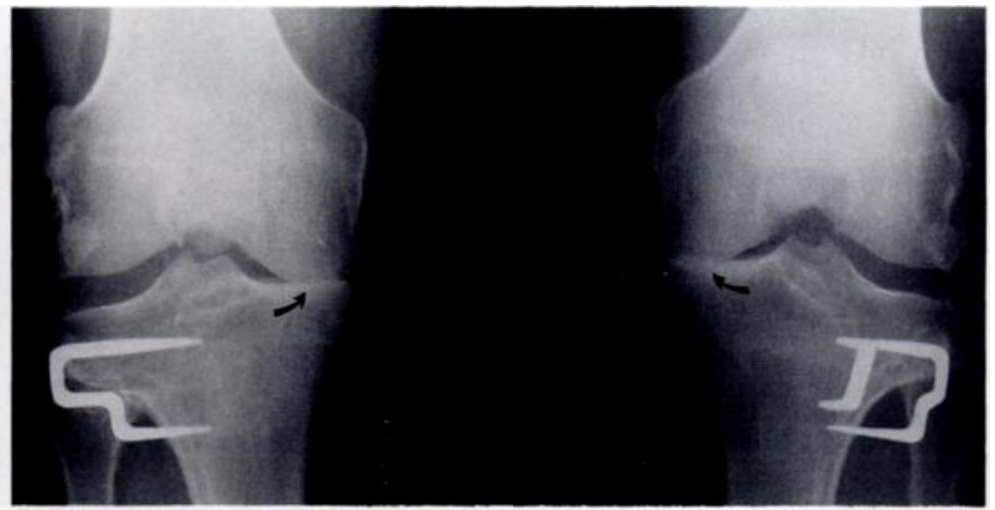

Fig. 3b

Conventional views and standing tunnel views of the same patient.

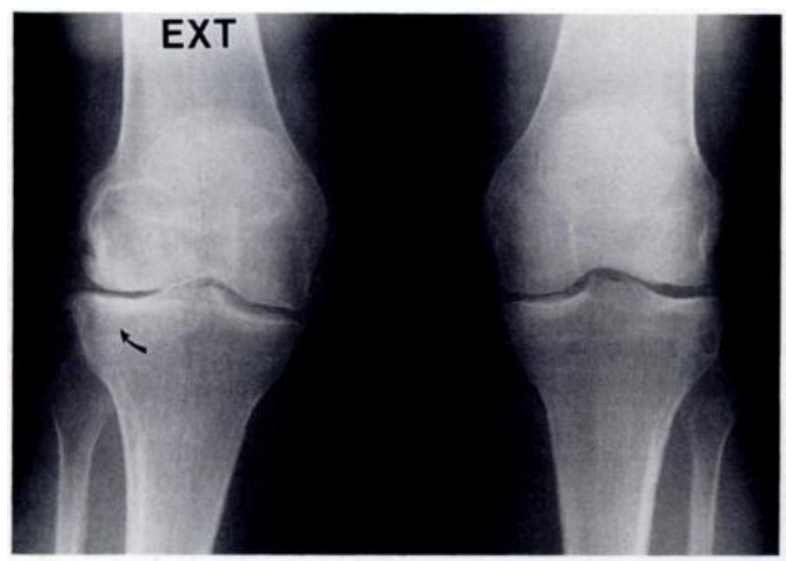

Fig. 4a

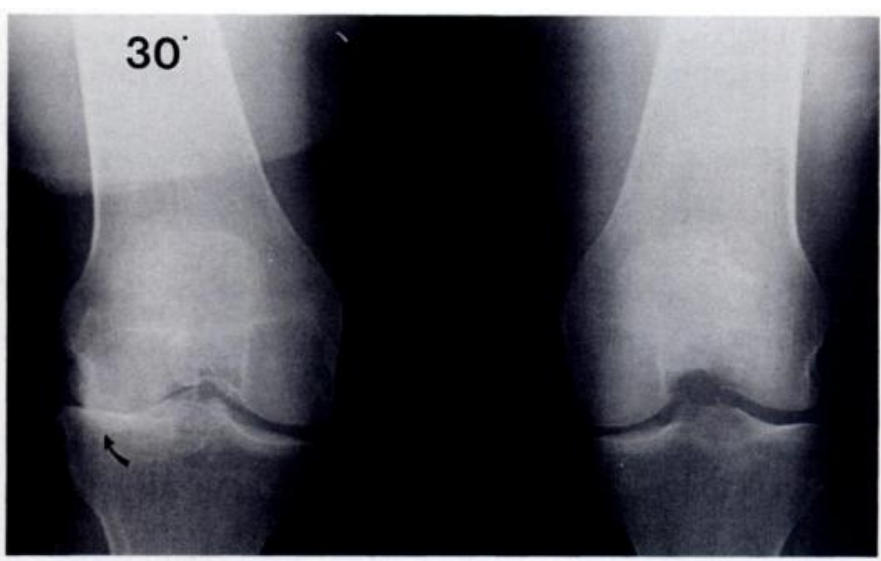

Fig. 4b

Conventional views and standing tunnel views of the same patient.

Maquet (1976) suggest that the major contact stresses in the tibiofemoral joint occur when the knee is in $24^{\circ}$ to $28^{\circ}$ of flexion. During the stance phase of gait the joint pressure may vary between 3 and $19 \mathrm{~kg} / \mathrm{cm}^{2}$ and the area of the weight-bearing surfaces may vary between $17 \mathrm{~cm}^{2}$ and $20 \mathrm{~cm}^{2}$, the smaller surface areas occurring in greatest flexion. During flexion these weight-bearing surfaces move backwards on the tibial plateaux as they become progressively smaller.

We have observed, by arthrotomy and arthroscopy,

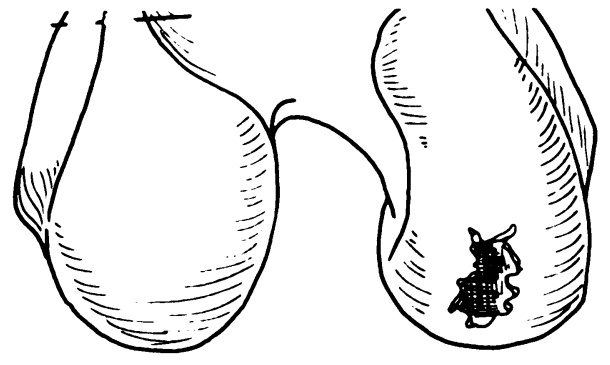

Fig. 5

Classical location of erosions on a femoral condyle. that cartilage loss occurs in a more posterior part of the femoral condyles than shown by the conventional standing view. Figure 5 illustrates the classical location of osteoarthritic erosions on a femoral condyle at a site which makes contact with the tibia near $30^{\circ}$ of flexion. If such a knee is extended and conventional weight-bearing views obtained, the cartilage space would appear normal since most anterior cartilage is well maintained.

No benefits in any form have been received or will be received from a commercial party related directly or indirectly to the subject of this article.

\section{REFERENCES}

Leach RE, Gregg T, Siber FJ. Weight-bearing radiography in osteoarthritis of the knee. Radiology 1970; 97:265-8.

Maquet PGJ. Biomechanics of the knee with application to the pathogenesis and the surgical treatment of osteoarthritis. Berlin, etc: SpringerVerlag, 1976.

Marklund T, Myrmets R. Radiographic determination of cartilage height in the knee joint. Acta Orthop Scand 1974; 45:752-5.

Railhac JJ, Fournie A, Gay R, Mansat M, Putois J. Exploration radiologique du genou de face en légère flexion et en charge: son intérêt dans le diagnostic de l'arthrose fémoro-tibiale. $J$ Radiol $1981 ; 62: 157-66$. (Eng. abstr.) 